\title{
Novel Bio-Logging Tool for Studying Fine-Scale Behaviors of Marine Turtles in Response to Sound
}

\section{OPEN ACCESS}

Edited by:

Ellen Hines,

San Francisco State University, United States

Reviewed by:

Nathan D. Merchant, Centre for Environment, Fisheries and Aquaculture Science, United Kingdom John A. Cigliano,

Cedar Crest College, United States

*Correspondence: Reny B. Tyson rtyson@mote.org

Specialty section: This article was submitted to Marine Conservation and Sustainability,

a section of the journal Frontiers in Marine Science

Received: 31 March 2017 Accepted: 26 June 2017 Published: 14 July 2017

Citation:

Tyson RB, Piniak WED, Domit C, Mann D, Hall M, Nowacek DP and

Fuentes MMPB (2017) Novel

Bio-Logging Tool for Studying Fine-Scale Behaviors of Marine Turtles in Response to Sound. Front. Mar. Sci. 4:219. doi: 10.3389/fmars.2017.00219

\author{
Reny B. Tyson ${ }^{1 *}$, Wendy E. D. Piniak ${ }^{2}$, Camila Domit ${ }^{3,4}$, David Mann ${ }^{5}$, Michael Hall ${ }^{5}$, \\ Douglas P. Nowacek ${ }^{6}$ and Mariana M. P. B. Fuentes ${ }^{7}$
}

\begin{abstract}
${ }^{1}$ Sarasota Dolphin Research Program, Chicago Zoological Society, Sarasota, FL, United States, ${ }^{2}$ Department of Environmental Studies, Gettysburg College, Gettysburg, PA, United States, ${ }^{3}$ Laboratório de Ecologia e Conservação, Centro de Estudos do Mar, Universidade Federal do Paraná, Paraná, Brazil, ${ }^{4}$ Associação MarBrasil, Paraná, Brazil, ${ }^{5}$ Loggerhead Instruments, Inc., Sarasota, FL, United States, ${ }^{6}$ Nicholas School of the Environment \& Pratt School of Engineering, Duke University Marine Laboratory, Beaufort, NC, United States, ${ }^{7}$ Department of Earth, Ocean, and Atmospheric Science, Florida State University, Tallahassee, FL, United States
\end{abstract}

Increases in the spatial scale and intensity of activities that produce marine anthropogenic sound highlight the importance of understanding the impacts and effects of sound on threatened species such as marine turtles. Marine turtles detect and behaviorally respond to low-frequency sounds, however few studies have directly examined their behavioral responses to specific types or intensities of anthropogenic or natural sounds. Recent advances in the development of bio-logging tools, which combine acoustic and fine-scale movement measurements, have allowed for evaluations of animal responses to sound. Here, we describe these tools and present a case study demonstrating the potential application of a newly developed technology (ROTAG, Loggerhead Instruments, Inc.) to examine behavioral responses of freely swimming marine turtles to sound. The ROTAG incorporates a three-axis accelerometer, gyroscope, and magnetometer to record the turtle's pitch, roll, and heading; a pressure sensor to record turtle depth; a hydrophone to record the turtle's received underwater acoustic sound field; a temperature gauge; and two VHF radio telemetry transmitters and antennas for tag and turtle tracking. Tags can be programmed to automatically release via a timed corrodible link several hours or days after deployment. We describe an example of the data collected with these tags and present a case study of a successful ROTAG deployment on a juvenile green turtle (Chelonia mydas) in the Paranaguá Estuary Complex, Brazil. The tag was deployed for $221 \mathrm{~min}$, during which several vessels passed closely $(<2 \mathrm{~km})$ by the turtle. The concurrent movement and acoustic data collected by the ROTAG were examined during these times to determine if the turtle responded to these anthropogenic sound sources. While fine-scale behavioral responses were not apparent (second-by-second), the turtle did appear to perform dives during which it remained still on or near the sea floor during several of the vessel passes. This case study provides proof of concept that ROTAGs can successfully be applied to free-ranging marine turtles to examine their behavioral response to sound. Finally, we discuss the broad applications that these tools have to study the fine-scale behaviors of marine turtles and highlight their use to aid in marine turtle conservation and management.

Keywords: bio-logging, tagging, marine turtle, anthropogenic sound, behavioral response 


\section{INTRODUCTION}

Increases in the spatial scale and intensity of activities that produce anthropogenic sound in the marine environment have led to a rapid growth in the number and scope of scientific studies that assess the potential physiological and behavioral impacts of anthropogenic sound on marine organisms (Richardson et al., 1995; National Research Council, 2000, 2003, 2005; Nowacek et al., 2007; Popper and Hastings, 2009). Sounds produced by anthropogenic activities such as shipping, seismic surveys, dredging, pile driving, low-frequency sonar, and wind turbines have been shown to induce stress in organisms such as marine mammals and fish, which may contribute to suppressed growth, reproduction, and immune system functioning (Romano et al., 2004; Wright et al., 2007; Rolland et al., 2012), to elicit behavioral responses (e.g., Richardson et al., 1995; Nowacek et al., 2007; Popper and Hastings, 2009), and to cause temporary and permanent threshold shifts in hearing (reviwed by Finneran, 2015). Anthropogenic sound may also mask important acoustic cues that marine species rely on for communication, navigation, foraging, or reproduction (Richardson et al., 1995; Halpern et al., 2008). Most of the research to date on effects of anthropogenic sounds on marine species has focused on marine mammals and fishes (reviewed by Nowacek et al., 2007; Slabbekoorn et al., 2010), with substantial knowledge gaps remaining in relation to the responses of marine turtles to sound (Popper et al., 2014). While marine turtles are known to detect and respond to lowfrequency acoustic stimuli (i.e., 50-2,000 Hz) (Ridgway et al., 1969; O'hara and Wilcox, 1990; Bartol et al., 1999; McCauley et al., 2000; Bartol and Ketten, 2006; DeRuiter and Doukara, 2012; Martin et al., 2012; Piniak, 2012; Lavender et al., 2014; Piniak et al., 2016); such as those commonly produced by anthropogenic activities (Hildebrand, 2009), further research is needed to examine the extent that such activities may affect the behavior and physiology of marine turtles (Popper et al., 2014; Nelms et al., 2016).

The few behavioral studies conducted with marine turtles in response to sound have primarily been conducted in enclosed or semi-enclosed settings, and in response to high-intensity seismic air guns, limiting the ability to assess behaviors of freely swimming turtles to specific types, levels, and frequencies of anthropogenic sound. For example, McCauley et al. (2000) exposed a green (Chelonia mydas) and a loggerhead turtle (Caretta caretta) to an approaching-departing single air gun in a cage and found that the turtles increased their swimming activity when the air gun sound levels were equivalent to $166 \mathrm{~dB}$ re $1 \mu \mathrm{Pa}$, and that they demonstrated more erratic behavior at sound levels greater than $175 \mathrm{~dB}$ re $1 \mu \mathrm{Pa}$, possibly indicating an agitated state. Alternatively, O'hara and Wilcox (1990) found that loggerhead turtles generally remained near or moved toward the sound source when exposed to air guns in a $300 \times 45$ enclosure in a $10 \mathrm{~m}$ deep canal, but they did not report sound levels. Finally, Moein et al. (1994) reported that repeated exposure of loggerhead turtles to air guns in an $18 \mathrm{~m} \times 61 \mathrm{~m}$ enclosure in a $3.6 \mathrm{~m}$ river exhibited avoidance behavior upon the first presentation of the stimulus, but that repeated exposure did not elicit significant behavioral responses, suggesting that the turtles had habituated to the sound or had temporary shifts in hearing capabilities (sound source ranges were not reported). Physiological measurements showed increases in stress levels, and pre- and post-hearing threshold measurements showed a temporary decrease in hearing sensitivity in some turtles after seismic air gun exposures. To our knowledge the only studies conducted on free-swimming marine turtles in an open water environment were conducted by DeRuiter and Doukara (2012) and Weir (2007), whom visually tracked loggerhead turtles during seismic air gun surveys. The two studies report contrasting results with DeRuiter and Doukara (2012) documenting that loggerhead turtles dove immediately following an air gun shot (estimated received level of $191 \mathrm{~dB}$ re $1 \mu$ Pa-peak at $130 \mathrm{~m}$ and $175 \mathrm{~dB}$ re $1 \mu$ Pa-peak at $830 \mathrm{~m}$ ), possibly eliciting a startle response, and Weir (2007) reporting that $80 \%$ of olive ridley turtles (Lepidochelys olivacea) remained at the surface during air gun activity. The differences between the two studies could be related to variations in behavioral responses by different species, variations in air gun source levels, frequencies, and/or distances, or some other unknown environmental or ecological parameter. These differences and the lack of additional studies available examining marine turtle responses to anthropogenic sound, particularly in open water environments, highlight the urgent need to develop tools and techniques that enable us to fill this important research gap.

Studying the movements and behaviors of free-swimming marine animals, especially in relation to sound sources, has many logistical challenges, but the advent and use of biologging tools, such as radio, acoustic, or satellite-telemetry tags and data archival tags has greatly expanded the capacity to conduct such analyses. Bio-logging tools can provide insights into the behaviors and movements of marine species over long and broad temporal and spatial scales as well as at depths where these animals are not visible. Therefore, they are an increasingly popular method for examining the movements, behaviors, physiology, and/or environment of free-ranging marine megafauna, including marine turtles (Payne et al., 2014). For example, satellite tags have been used to document the broad-scale movements of marine turtles, as well as to infer their home range, migratory corridors, suitable habitats, and exposure to threats (e.g., reviewed by Godley et al., 2008). In addition, passive and active acoustic telemetry tags (e.g., Taquet et al., 2006; Lamont et al., 2015), time-depth recorders (TDRs; e.g., Eckert et al., 1989; Hill et al., 2016), and animal-borne video tags (e.g., Seminoff et al., 2006; Arthur et al., 2007) have been used to infer fine-scale movements and behaviors of animals, particularly in relation to foraging ecology and diving behavior. Bio-logging tools that combine acoustic and fine-scale movement measurements (e.g., digital acoustic recording tags, Dtags, Johnson and Tyack, 2003; Acousonde, Burgess, 2009) are a particularly useful tool for quantifying behaviors of marine organisms in response to sound; however, to our knowledge have not yet been applied with marine turtles. These tools are commonly used in behavioral response studies (BRS) and controlled exposure experiments (CEEs) of marine mammals whereby a specific stimulus [e.g., sonar, predatory acoustic cues, an acoustic deterrent device (ADD)] is played to an individual that is fitted with a tag, which measures the animal's response as 
well as the received sounds, thus providing a combined record of stimulus and response (e.g., Johnson et al., 2009; Tyack, 2009; Tyack et al., 2011; Southall et al., 2012; DeRuiter et al., 2013; Goldbogen et al., 2013; Stimpert et al., 2014; Harris et al., 2016; Southall et al., 2016). These tools can also be used passively to examine an animal's behavior in relation to sounds in their environment, such as sounds produced by the tagged individual (e.g., Tyson et al., 2007; Stimpert et al., 2012; Sayigh et al., 2013), calls from conspecifics (e.g., Jensen et al., 2011) or predators (e.g., Curé et al., 2013; Bowers, 2015), and anthropogenic sound sources such as noise produced by shipping and small vessels (e.g., Aguilar Soto et al., 2006; Jensen et al., 2009; Parks et al., 2011).

In this paper, we introduce the application of the RemoraOpenTag (ROTAG), a fine-scale digital acoustic and movement tag custom designed by Loggerhead Instruments, Inc. for use with free-ranging marine turtles. We include a description of the ROTAG and demonstrate proof-of-concept via a case study of a successful deployment on a juvenile green turtle in the Paranaguá Estuarine Complex (PEC) off Paraná state in southern Brazil. Because the habitat use of marine turtles overlaps extensively with sound produced by anthropogenic activities such as fishing, shipping, and coastal and marine development (Van Dolah and Maier, 1993; Wallace et al., 2010; Lewison et al., 2014; Fuentes et al., 2016), the application of the ROTAG will enable researchers to gain important insights regarding how and to what extent such activities may affect marine turtles. This information is critically needed and can be used to aid in marine turtle conservation and management.

\section{ROTAG DESCRIPTION}

The ROTAG is a fine-scale digital acoustic and movement tag designed and developed by Loggerhead Instruments, Inc. specifically for use with marine turtles. The system combines an Arduino-compatible open-source inertial measurement unit (IMU) for recording high speed motion sensor data (OpenTag motion datalogger, Loggerhead Instruments Inc.) with a stateof-the-art acoustic tag for measuring sound in the marine environment (Remora-ST, Loggerhead Instruments, Inc.) and a rechargeable lithium polymer battery encapsulated with epoxy (Epotek 301) in a 3D printed ABS plastic housing pressure tolerant to $300 \mathrm{~m}$ depth (Figure 1). The tag is designed to sit upon an ABS plastic plate $(4.45 \times 4.06 \mathrm{~cm}, 0.64$ in thickness $)$ that is affixed to a turtle's carapace with epoxy (e.g., Sonic Weld). A 0.22 $\mathrm{mm}$ stainless steel wire is used to attach the ROTAG to this plate, and can be programmed to corrode at a specified time to release the ROTAG from the plate and the turtle. A positively buoyant syntactic foam float is attached to the anterior portion of the tag to allow for the tag to float upon release from the turtle. Two VHF radio telemetry transmitters and antennas are positioned within the ROTAG to allow for tag and turtle tracking as well as retrieval of the tag: one antenna $(218-220 \mathrm{MHz})$ is positioned to transmit signals when the turtle surfaces to breath, while the other antenna $(149-150 \mathrm{MHz})$ is positioned to transmit signals when the tag is floating after release. The tag is powered by three $850 \mathrm{~mA}$ rechargeable lithium polymer batteries, and the total power draw is $\sim 25 \mathrm{~mA}$. The dimensions of the ROTAG body and float are 25 $\times 5 \times 2.8 \mathrm{~cm}$ and the in-air the tag weighs $220 \mathrm{~g}$. The shape was chosen to minimize the cross-sectional area exposed to flow in order to minimize drag.

The movement tag within the ROTAG includes a three-axis accelerometer, gyroscope, and magnetometer (sampling rate up to $100 \mathrm{~Hz}$ ), which can be used to calculate a turtle's pitch, roll, and heading; a pressure sensor (1 $\mathrm{Hz}$ sampling rate) to record turtle depth; and a temperature sensor ( $1 \mathrm{~Hz}$ sampling rate) to record ambient water temperature. Data recorded by this tag is stored on a micro SD memory card that can be removed from the device and saved to a computer after a successful deployment. The acoustic tag within the ROTAG can be programed to sample sound at $24,48,72,96,144$, or $288 \mathrm{kHz}$ with memory capabilities of $128 \mathrm{~GB}$ with $\mathrm{X} 3$ compression. The tag can be connected to a computer via a USB cable to download acoustic files after a deployment. The hydrophone of the acoustic tag has a sensitivity of $-211 \mathrm{dBV} / \mu \mathrm{Pa}$ and can be set to have either low $(21 \mathrm{~dB}$ gain $\sim 190 \mathrm{~dB}$ re $1 \mu \mathrm{PA}$ clip level) or high gain (33 dB gain $\sim 178 \mathrm{~dB}$ re $1 \mu$ Pa clip level).

The ROTAG can be customized in many ways depending on the user's needs. For example, the movement tag can stream all internal sensors (accelerometer, magnetometer, and gyroscope) at $100 \mathrm{~Hz}$ each. However, a user can choose to only record data from a specific sensor (e.g., accelerometer) at a higher sample rate without data loss (e.g., $200 \mathrm{~Hz}$ ). The ROTAG can also be set to record all data streams continuously or with a specified duty cycle. This includes an option to turn off the VHF transmitter at specified depths (e.g., greater than $1 \mathrm{~m}$ ), which may be beneficial as the frequencies emitted by the VHF transmitter can be received by the acoustic tag possibly hindering acoustic measurements. In addition specific sensors could be set to turn on upon motion detection (i.e., data will be recorded for a specified duration when a defined threshold is exceeded on the accelerometer). The deployment duration of the ROTAG depends on these userspecified settings, but ranges from $\sim 3-7$ days.

\section{CASE STUDY: ROTAG DEPLOYMENT ON A JUVENILE GREEN TURTLE}

On 26 May 2016 we deployed a ROTAG on a juvenile green turtle during a pilot study conducted in the PEC (Figure 2). The results of the pilot study are reported elsewhere (see Tyson et al. unpublished report 2016), but data collected during this deployment are described here to showcase how ROTAGs can be used to examine marine turtle behavior and concurrent anthropogenic sound.

A local fisherman captured the turtle using a bottomset gillnet on the morning of 26 May 2016. The turtle was transferred by boat to our research team $\sim 1 \mathrm{~h}$ after capture. A veterinarian assessed the turtle's health (e.g., body condition, behavior, presence of fibropapilloma or other external pathologies and injuries), which was deemed to be good, and we collected standard morphometric measurements: the turtle weighed $12.28 \mathrm{~kg}$ and its curved carapace length was $38.50 \mathrm{~cm}$ 


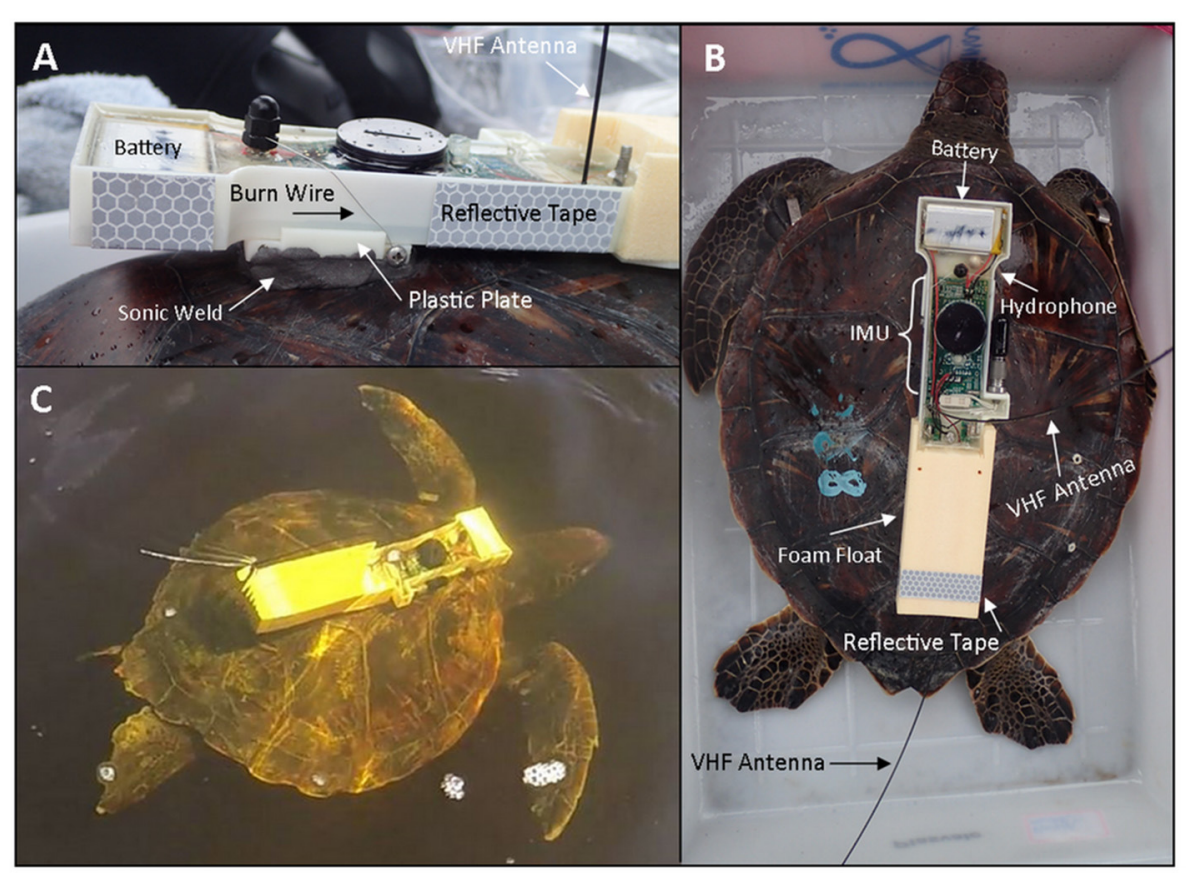

FIGURE 1 | A ROTAG deployed on a juvenile green turtle. (A) A side view of the ROTAG affixed to the turtle's carapace. A 0.22 mm stainless steel wire attaches the ROTAG to a plastic plate that is affixed to the turtle's carapace with epoxy. Reflective tape is included to assist with tag retrieval at night. (B) An overhead view of the ROTAG affixed to a turtle, indicating the main components of the tag. (C) A freely-swimming juvenile green turtle with a ROTAG. Once the burn is complete the tag will release from the plate and float to the surface. The small plastic plate will remain affixed to the turtle until it is worn off.

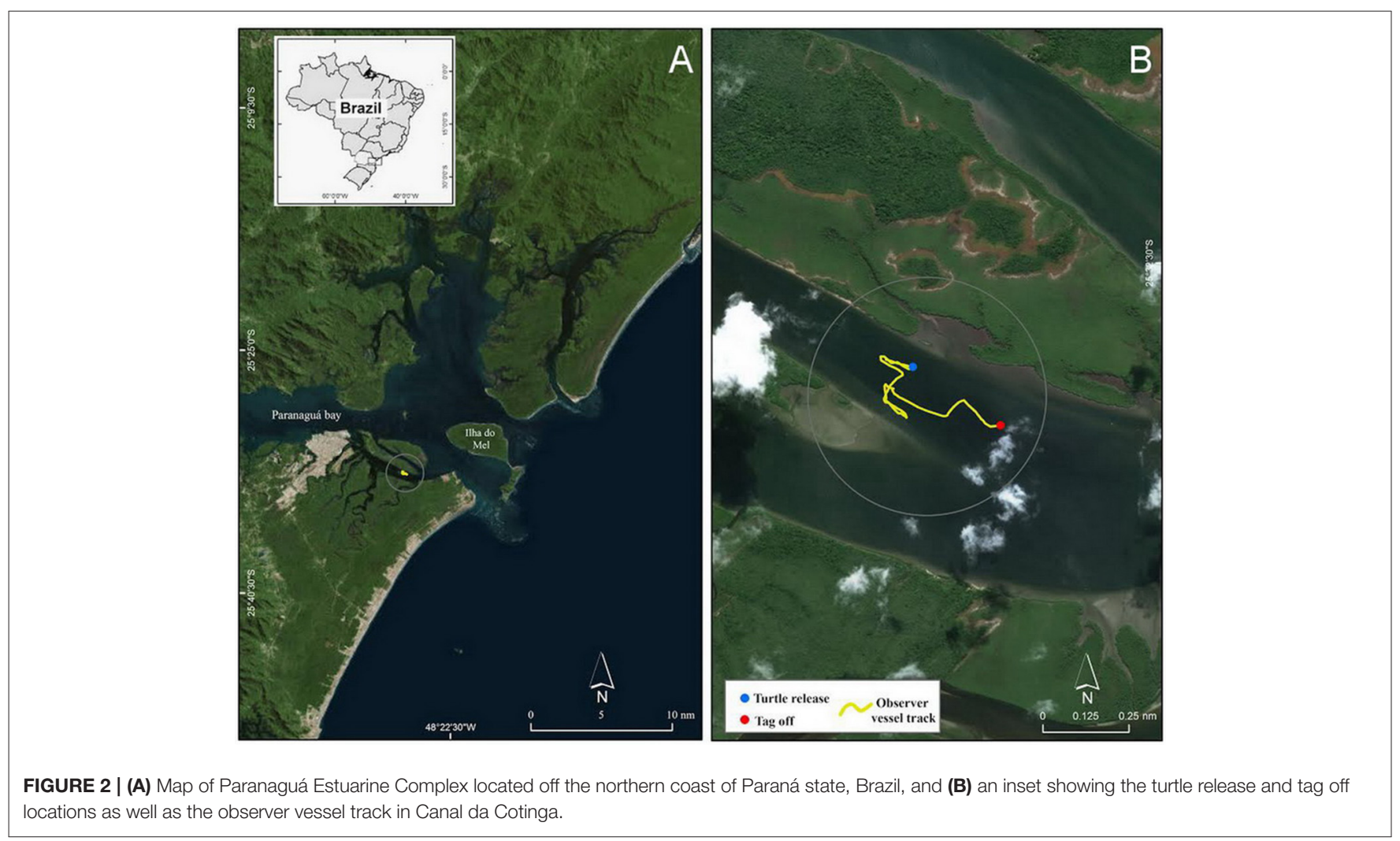


and curved carapace width was $36.90 \mathrm{~cm}$. Prior to tag attachment, we cleaned the anterior portion of the turtle's carapace of barnacles and other epibionts, sanded it with coarse sandpaper (e.g., 60-grit), and washed it with distilled water, 91\% isopropyl, and acetone to increase bonding strength. We applied a steelreinforced epoxy (Sonic-Weld) to the base of the plastic plate to which the ROTAG was attached and placed the plate on the 2nd vertebral scute for (Figure 1). Following SEFSC (2008) protocols, the total weight of the tag plus epoxy used for attachment was less than $5 \%$ of the turtle's body weight, minimizing the effects from increased drag and mass. Preliminary analyses by Tyson et al. (2016) using ROTAGs deployed in this manner report that respirations of a turtle before and during a deployment were statistically similar, suggesting minimal behavioral interference from the tags.

We waited $\sim 10$ min for the epoxy to dry then released the turtle at 13:23:36 local time ( -3 GMT) in Canal da Cotinga, an estuarine area surrounded by mangroves (Figures 1C, 2). We programmed the ROTAG to sample the accelerometer, magnetometer, and gyroscope at $100 \mathrm{~Hz}$ and the pressure and temperature sensors at $1 \mathrm{~Hz}$. We recorded sound at $96 \mathrm{kHz}$ with a low gain. We also programmed the ROTAG to turn off the VHF signal when the turtle was $\geq 10 \mathrm{~m}$ and to activate the wire attaching the ROTAG to the fixed plastic plate to start burning $250 \mathrm{~min}$ after the tag start time (i.e., just before dusk) to initiate tag release. During the deployment we tracked the turtle via the integrated radio telemetry tags and a VHF receiver and antenna from an observation vessel (26 foot center console vessel with two $150 \mathrm{Hp}$ engines) positioned $>200 \mathrm{~m}$ from the perceived turtle's location. As we rarely visually spotted the turtle, these observations consisted primarily of recordings of the time points for which we heard the VHF signal, which was indicative of the turtle being at the surface to breathe. We also recorded other events of interest, such as the presence of any vessels near the perceived turtle's location (i.e., within $\sim 2 \mathrm{~km}$ ). As scheduled, at 16:50:00 the wire burn was initiated and at 17:04:50 the ROTAG released from the turtle and floated to the surface. Upon retrieval, we downloaded the ROTAG data onto a computer for analysis.

We extracted and calibrated the movement data using custom written code in the R Statistical Program (R Core Team, 2016). We used the pressure and temperature sensor data to estimate depth and temperature, respectively (Figures 3A,B). The turtle dove 30 times during the deployment (dives were considered to be any submergence greater than 0.2 meters deep and longer than $5 \mathrm{~s}$ ). Maximum dive depths (mean (median) \pm SD) were 6.22 $(6.78) \pm 3.01 \mathrm{~m}$, dive durations were $408.53(256.00) \pm 399.04$ $\mathrm{s}$, and post-dive surface durations were $22.80(13.50) \pm 23.04$ s. Temperature was $21.17(21.09) \pm 0.21^{\circ} \mathrm{C}$. The large decrease in temperature seen at the beginning of the deployment record and during surfacings (Figure 3B) corresponds to the ROTAG transitioning from air to water temperatures. We subsampled the accelerometer and magnetometer data to $5 \mathrm{~Hz}$ and used them to calculate the pitch, roll, and heading of the tagged turtle as well as the vector of the dynamic body acceleration (VeDBA), a proxy for energy expenditure (Qasem et al., 2012; Figures 3C-F, respectively). These parameters demonstrated variations in movements while the turtle was diving and minimal

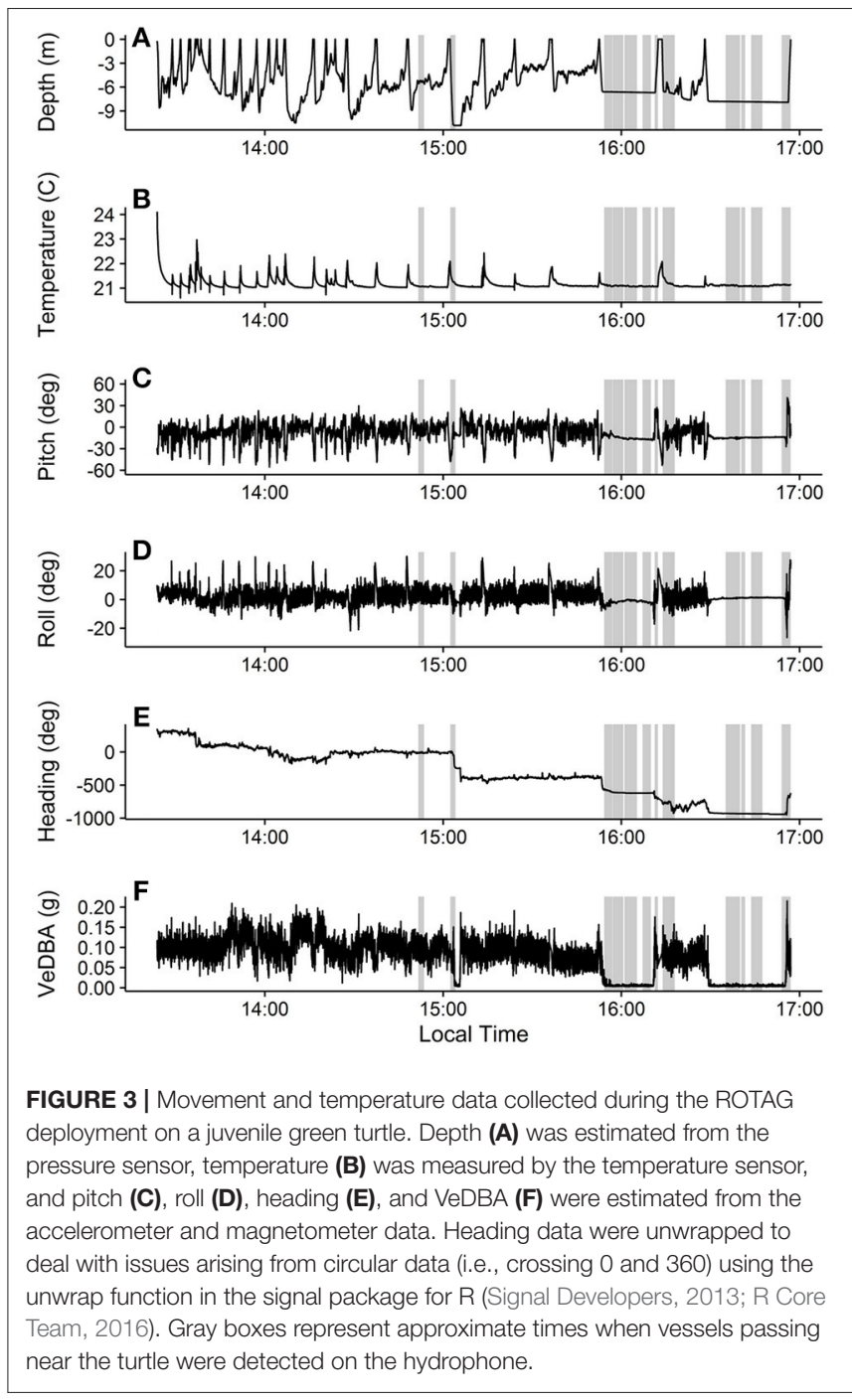

movement when the turtle was resting at or near the sea floor.

The acoustic data from the ROTAG was examined using Adobe Audition ${ }^{\circledR}$ (V1 Build 3211.2) and analyzed using the Fast Fourier Transformation (FFT) with 4,096 points FFT order, Hanning windows, and a $50 \%$ overlapping of successive windows. From this examination, we were able to pinpoint the start and end time points of all instances when vessels passed closely by the turtle (estimated distance is $<2 \mathrm{~km}$ given the location of the observation vessel and surrounding land masses) (Figure 3). During many of these instances, the turtle appears to remain still on or near the sea floor. Figure 4 showcases the movements of the turtle and the corresponding spectrogram of sounds for the dive that occurred from 15:52:36 to $16: 12: 24$. While there is no clear behavioral response between individual boat passes and turtle behavior (despite the slight change in pitch, roll, heading at VeDBA at $\sim 15: 56: 33$ ), this schematic showcases how useful the information recorded on these tags can be in examining turtle behaviors in response to anthropogenic sound. Spectrum levels of 

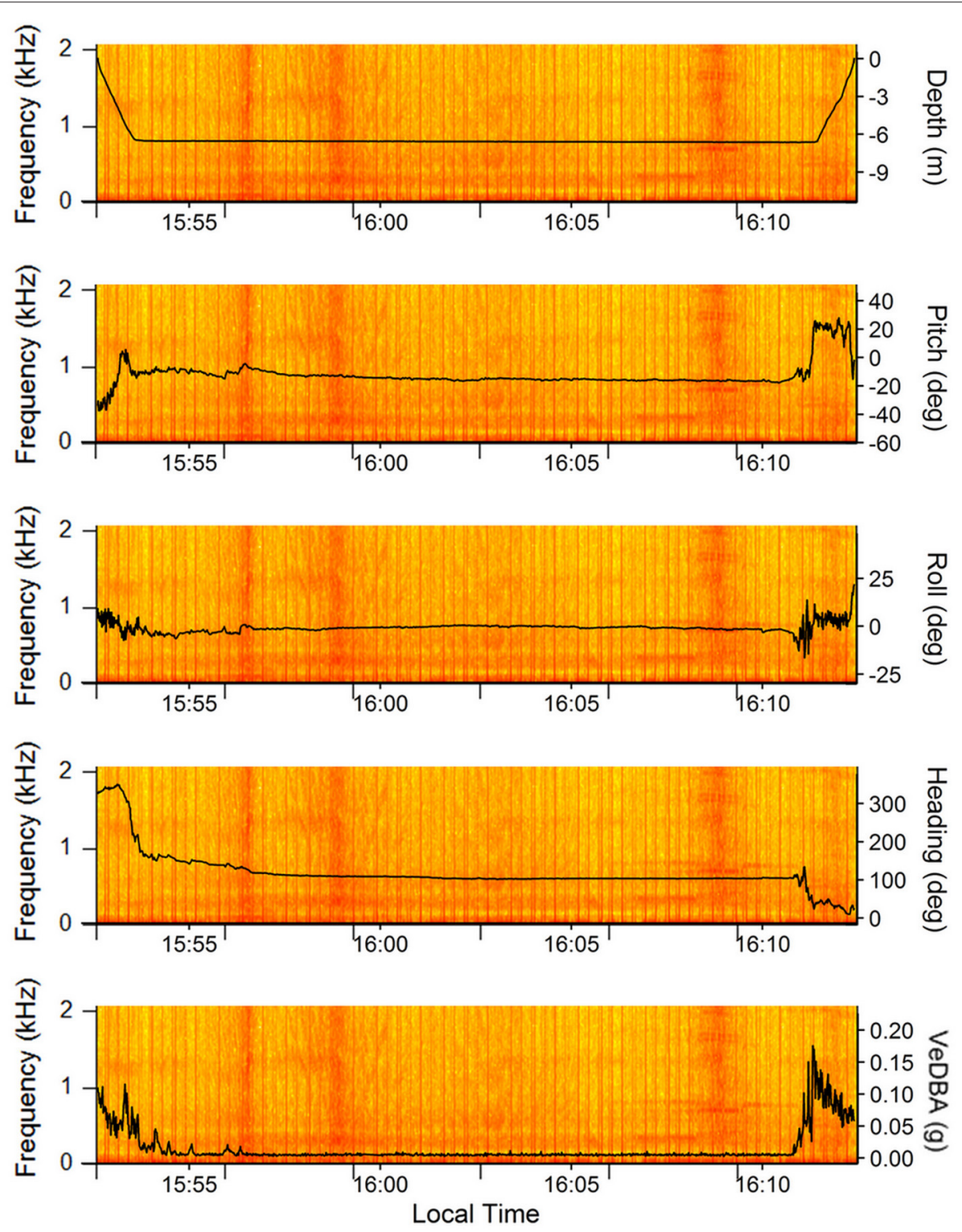

Amplitude (dB)

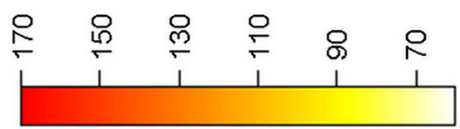

FIGURE 4 | Depth, pitch, roll, heading, and VeDBA of the juvenile green turtle during a dive with multiple vessel passes overlaid onto the simultaneous acoustic record (i.e., spectrogram). The vessel passes are the broadband signals with varying amplitudes and durations found at 15:56:28, 15:58:50, 16:03:05, 16:08:44, and 16:10:36. VHF transmitter signals picked up by the audio board are apparent as regularly spaced broadband clicks of consistent sound pressure levels. Spectrograms were created in R using the spectro function in the seewave package for R (Sueur et al., 2008; R Core Team, 2016) with 4,096 points FFT order, Hanning windows, and a 50\% overlapping of successive windows.

the vessels (Figure 4) were measured and compared to an average audiogram of a green turtle in Figure 5.

Spectra for noise level measurements were calculated by isolating 32,768 points in between the VHF pings. A Hanning window was applied to each segment and a FFT calculated (frequency resolution $=2.93 \mathrm{~Hz}$ ) using MATLAB. Spectrum level was calculated by adjusting for the hydrophone sensitivity, gain,
Hanning window $(+6 \mathrm{~dB})$, and subtracting $10(\log ($ frequency resolution)). Ten sequential spectra were averaged to calculate an average spectrum level that covered about $5 \mathrm{~s}$ of recording time from the original recording (Figure 5). While these vessels produce generally broadband signals (Figure 4), the turtle may have detected their presence as the spectrum levels of all vessels were above their hearing thresholds, specifically in the 200-400 


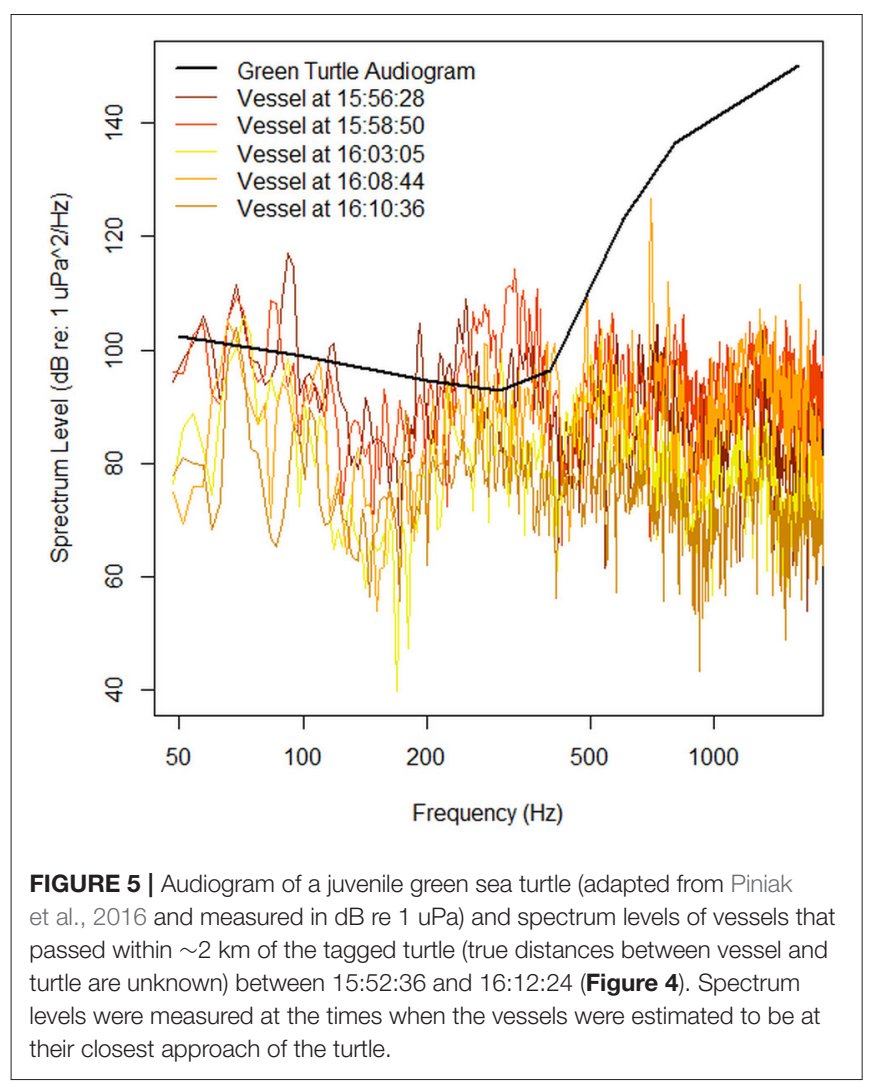

$\mathrm{Hz}$ range. Even if detected; however, the turtle may not have responded because the measured spectrum levels were much lower than those previously shown to illicit behavioral responses in turtles (Figure 5; e.g., $\geq 166 \mathrm{~dB}$ re $1 \mu \mathrm{Pa}$, McCauley et al., 2000). In addition, during the $221 \mathrm{~min}$ of the deployment, 13 vessels passed closely by the turtle. Therefore, it is likely that this turtle is either habituated to the sounds produced by these vessels or that they have experienced some level of hearing loss due to their constant presence. More records of vessels near tagged turtles, their approximate distances, and estimates of their spectrum levels are needed to determine if turtles, such as the one presented here, responded to the sounds produced by vessels such as this and if so what this response may be (e.g., remain still on sea floor, surface, swim away).

\section{RO-TAG APPLICATIONS}

Marine turtle populations have experienced severe declines globally due to direct harvest, incidental capture in fisheries, and the destruction of foraging and nesting habitats (Lutcavage et al., 1996; Wallace et al., 2011a,b). Because the habitat use of marine turtles overlaps extensively with anthropogenic activities that produce sounds such as fishing, shipping, and coastal and marine development (Van Dolah and Maier, 1993; Wallace et al., 2010; Lewison et al., 2014; Fuentes et al., 2016) it is important to develop tools and techniques that enable us to examine how such activities affect the behavior and physiology of these threatened species. The case study presented here showcasing a successful deployment of a ROTAG on a juvenile green turtle provides proof of concept for using these tags to examine marine turtles in response to sound and demonstrates their utility in examining the general soundscapes of marine turtles. These advancements will increase our understanding of the acoustic threats marine turtles face and can be used to aid in their successful conservation and management.

Marine species such as fish and marine mammals have been observed to respond to anthropogenic sounds produced at construction and demolition sites (e.g., Popper and Hastings, 2009; Buckstaff et al., 2013), by vessels (e.g., Aguilar Soto et al., 2006; Lemon et al., 2006; Jensen et al., 2009; Parks et al., 2011), and from low-frequency sonar (DeRuiter et al., 2013; Goldbogen et al., 2013). At this time, it is unknown whether free-ranging marine turtles respond to such sounds and to what extent their responses may be if present. Given that the sounds produced by many of these activities dominate the frequencies within the range of best hearing for marine turtles (50-500 Hz; Hildebrand, 2009) turtles are particularly susceptible to their presence. The ability to tag a turtle with a tool such as a ROTAG would enable researchers to examine if turtles respond to these types of anthropogenic activities, and if so the type and potential fitness consequences of these responses. For example, Goldbogen et al. (2013) and DeRuiter et al. (2013) used DTAGs, a bio-logging tool from which the ROTAG is based, to examine whether blue whales (Balaenoptera musculus) or Cuvier's beaked whales (Ziphius cavirostris) responded to midfrequency $(1-10 \mathrm{kHz})$ active (MFA) sonar. Both species exhibited responses to the MFA sonar: blue whales ceased deep activities, increased their swimming speed, and directed travel away from the sound source (Goldbogen et al., 2013). Cuvier's beaked whales (Ziphius cavirostris) responded by ceasing normal fluking and echolocation, and swimming rapidly and silently away from the sound source extending both their dive duration and subsequent non-foraging interval (DeRuiter et al., 2013). Similar insights in behavioral responses of marine turtles to sound can be obtained from the tags presented here (e.g., significant changes in parameters such as dive depth, heading, VeDBA, or dive duration) and could be used to help managers and policymakers to develop appropriate mitigation strategies, enact restrictions or legislation to limit such activities, and guide monitoring programs in regions where marine turtles may be present and vulnerable.

Sound has also been used to warn or repel animals from dangerous areas or activities. For example, one such anthropogenic activity of particular concern to marine turtles is dredging to sustain the demand for sediment (e.g., for beach nourishment projects), and maritime development (e.g., ports) to maintain shipping channels (Dickerson et al., 2004; Sundin, 2007; Goldberg et al., 2015). Dredging is often conducted with hopper dredges, which remove sediment through suction (Banks and Alexander, 1994; Goldberg et al., 2015). The hopper dredge dragheads are slow-moving and nearly silent and can cause physical harm (e.g., injuries, fractures, and hemorrhage) and mortality to marine turtles and impacts to their habitat (Dickerson et al., 1991, 2004; Banks and 
Alexander, 1994; Goldberg et al., 2015). Strategies to mitigate impacts of dredging on marine turtles and their habitat include: relocating marine turtles away from dredging sites (Dickerson et al., 2007; Sundin, 2007), modifications to hopper dredges drag heads (Banks and Alexander, 1994), and temporal restrictions to reduce the likelihood of turtle and hopper dredger interactions (Dickerson et al., 2004). Another potential strategy for minimizing interactions of marine turtles with anthropogenic activities, including dredging, is to warn or repel marine turtles from areas where potentially harmful activities are or will take place. Given that marine turtles can detect and respond to low-frequency acoustic stimuli, acoustic harassment devices (AHDs) and acoustic deterrent devices (ADDs) could be used as a strategy to successfully repel marine turtles from various threats, including from areas that are being dredged or potentially high interaction fishing areas (Van Der Meij et al., 2015). The ROTAG could be used to test and determine the effectiveness of various ADDs or AHDs providing insights into further development of these devices and their suitability as mitigation strategies to protect marine turtles.

While little evidence exists that sea turtles use sound for communication, sea turtles may use sound for navigation, locating prey, predator avoidance and environmental awareness (Piniak et al., 2016). It is likely that they, like other vertebrates, use ambient soundscapes to create an auditory scene that can provide them with critical information about their environment and their position (Bregman, 1990; Slabbekoorn and Bouton, 2008). For instance, the sound of waves crashing on a beach could indicate that they were close to shore, or near an appropriate nesting beach. The sounds of chorusing fish or snapping shrimp could provide a signpost that they were near an appropriate foraging area like an estuary or coral reef. Anthropogenic sounds have the potential to mask some of these important soundscape auditory cues. The biological significance of sound for marine turtles is not well understood, and the use of a ROTAG to describe the overall soundscape of turtles could provide interesting and important information regarding their ecology and biology that to date have been hard to obtain.

\section{SUMMARY AND CONCLUSIONS}

The case study presented here provides proof of concept that ROTAGS can successfully be applied to free-ranging marine turtles. The information available from these tools can be used in a variety of ways for marine turtle conservation and ecology in particular to determine the response of marine turtles to anthropogenic sound. While these tags are useful for many applications, several limitations still exist at this time. Being high-resolution recording tags, ROTAGs can only be deployed on turtles for a short period of time (i.e., $\sim 3-7$ days depending on user settings). However, the richness and breadth of the data collected by ROTAGs cannot currently be obtained with longer-term bio-logging tags, such as satellite tags or other time-depth recorders, and therefore can be used to enhance our understanding of fine-scale marine turtle behavior, specifically in relation to sound. Another limitation common to all capture/release and tagging studies, the possibility of inducing a capture and/or tagging response by the animal under study, is something that needs to be considered. For example, Thomson and Heithaus (2014) and Hazel et al. (2009) found that some green turtles fitted with animal borne video cameras and TDRs, respectively, were influenced by capture stress for several hours (0-6) after release. In contrast Seminoff et al. (2006) reported that turtles tagged with a Crittercam ${ }^{\mathrm{TM}}$ resumed normal activities within minutes of being released. The ROTAG will create drag for the turtle, which may result in modified swimming behaviors. For example, van der Hoop et al. (2014) found that bottlenose dolphins carrying DTAGs swam more slowly than dolphins without DTAGs possibly in an effort to reduce the metabolic cost of drag created from the tags. Drag may also be induced by the plastic plate left affixed to the turtle after the ROTAG is released (Jones et al., 2013), but given the low profile of the plate we anticipate this drag to be minimal. More deployments are needed to further investigate whether a capture or tagging response is elicited with ROTAGS and if so how they can be minimized. Finally, the presence of flow noise recorded by the tags, which increases with decreasing frequency (Burgess et al., 1998; Merchant et al., 2015), may mask sounds of interest within the range of marine turtles best hearing (i.e., $<2,000 \mathrm{~Hz}$ ). In the case study presented here; however, flow noise was typically at frequencies less than $70 \mathrm{~Hz}$ (e.g., Figure 4) and therefore was minimal.

Given the threatened status of many species and populations of marine turtle, mitigation measures are needed, and often required by laws and regulations, to reduce marine turtle injuries and mortalities associated with these activities (Wallace et al., 2013; Fuentes et al., 2015). Until the threat of anthropogenic sound on marine turtles can be assessed, such mitigation measures may be unproductive in conserving these species. The application of the ROTAG or similar acousticmovement tags will enable researchers to start addressing this potential threat and to determine in what ways and to what extent anthropogenic sound may impact marine turtles. This information can then be used to more appropriately guide laws and regulations devised for conserving these threatened species. In addition, the broad range of applications the ROTAG presents make it a unique tool for expanding our understanding of the fine-scale movements and behaviors of marine turtles, which may provide new insights into their ecology, such as their foraging behavior, physiology, and predator response.

\section{AUTHOR CONTRIBUTIONS}

RT, WP, CD, DN, and MF contributed to the acquisition, analysis, and interpretation of the data as well as by drafting and revising the manuscript. DM and $\mathrm{MH}$ designed and built the ROTAG used in this study and contributed to the analysis and interpretation of the data, as well as by revising intellectual content. 


\section{FUNDING}

This research was funded by Van Oord.

\section{ACKNOWLEDGMENTS}

We wish to thank Van Oord (www.VanOord.com) for funding this research, specifically Heidi van der meij and Remment ter Hoftede for their help in project execution. We also with to thank the Ecology and Conservation Laboratory of

\section{REFERENCES}

Aguilar Soto, N., Johnson, M., Madsen, P. T., Tyack, P. L., Bocconcelli, A., and Fabrizio Borsani, J. (2006). Does intense ship noise disrput foraging in deep-diving Cuvier's beaked whales (Ziphius cavirostris)? Mar. Mamm. Sci. 22, 690-699. doi: 10.1111/j.1748-7692.2006.00044.x

Arthur, K. E., O’Neil, J. M., Limpus, C. J., Abernathy, K., and Marshall, G. (2007). Using animal-borne imaging to assess green turtle (Chelonia mydas) foraging ecology in Moreton Bay, Australia. Mar. Technol. Soc. J. 41, 9-13. doi: $10.4031 / 002533207787441953$

Banks, G. E., and Alexander, M. P. (1994). Development and Evaluation of a Sea Turtle Deflecting Hopper Dredge Draghead. Washington, DC: U.S. Army Corps of Engineers.

Bartol, S. M., and Ketten, D. R. (2006). "Turtle and tuna hearing," in Sea Turtle and Pelagic Fish Sensory Biology: Developing Techniques to Reduce Sea Turtle Bycatch in Longline Fisheries, eds Y. Swimmer and R. Brill (Honolulu, HI: NOAA (Natl Ocean Atmos Adm) Tech Mem NMFS-PIFSC-7), 98-105.

Bartol, S. M., Musick, J. A., and Lenhardt, M. (1999). Auditory evoked potentials of the loggerhead sea turtle (Caretta caretta). Copeia 3, 836-840. doi: $10.2307 / 1447625$

Bowers, M. (2015). Behavioral Ecology of the Western Atlantic Short-finned Pilot Whale (Globicephala macrorhynchus). Ph.D., Duke University.

Bregman, A. S. (1990). Auditory Scene Analysis: The Perceptual Organization of Sound. Cambridge, MA: MIT Press.

Buckstaff, K. C., Wells, R. S., Gannon, J. G., and Nowacek, D. P. (2013). Responses of bottlenose dolphins (Tursiops truncatus) to construction and demolition of coastal marine structures. Aquat. Mamm. 39:174. doi: 10.1578/AM.39.2.2013.174

Burgess, W. C. (2009). The Acousonde: a miniture autonomous wideband recorder. J. Acoust. Soc. Am. 125, 2588-2588. doi: 10.1121/1.4783838

Burgess, W. C., Tyack, P. L., Le Boeuf, B. J., and Costa, D. P. (1998). A programmable acoustic recording tag and first results from free-ranging northern elephant seals. Deep Sea Res. II Top. Studi. Oceanogr. 45, 1327-1351. doi: 10.1016/S0967-0645(98)00032-0

Curé, C., Antunes, R., Alves, A. C., Visser, F., Kvadsheim, P. H., and Miller, P. J. (2013). Responses of male sperm whales (Physeter macrocephalus) to killer whale sounds: implications for anti-predator strategies. Sci. Rep. 3:1579. doi: $10.1038 /$ srep01579

DeRuiter, S. L., and Doukara, K. L. (2012). Loggerhead turtles dive in response to airgun sound exposure. Endanger. Species Res. 16, 55-63. doi: 10.3354/ esr00396

DeRuiter, S. L., Southall, B. L., Calambokidis, J., Zimmer, W. M. X., Sadykova, D., Falcone, E. A., et al. (2013). First direct measurements of behavioural responses by Cuivier's beaked whales to mid-frequency active (MFA) sonar. Biol. Lett. 9:20130223. doi: 10.1098/rsbl.2013.0223

Dickerson, D., Richardson, J. I., Ferris, J. S., Bass, A. L., and Wolf, M. (1991). Entrainment of sea turtles by hopper dredges in Cape Canaveral and King's Bay Ship Channels. Environ. Effect. Dredging 91, 1-9.

Dickerson, D., Theriot, C., Wolters, M., Slay, C., Bargo, T., and Parks, W. (2007). "Effectiveness of relocation trawling during hopper dredging for reducing incidental take of sea turtles," in 2007 World Dredging Conference. Available online at: https://www.westerndredging.org/phocadownload/Conference Presentations/2007_WODA_Florida/Session3C-USACE-ERDCResearchInitia the Federal University of Paraná, Brasil, and the MarBrasil Association (www.marbrasil.org) for their support during the field operations of this research. Thanks also go to Jerry Moxly, Gabriela M. Vélez Rubio, Daniel Gonzalez, Ignacio Matias-Bruno, Beatriz Neves, and Robin Hilbert Loose for their help in the field. All scientific activities were conducted under the Brazilian Scientific Permit from the Ministry of the Environment (SISBIO-43443-3) and the Florida State University Animal Care and Use permit FSU/ACUC $\# 1609$.

tives/2- Dickerson, et al - Relocation Trawling During Hopper Dredging and Sea Turtles.pdf

Dickerson, D., Wolters, M. S., Theriot, C. T., and Slay, C. (2004). "Dredging impacts on sea turtles in the Southeastern USA: a historical review of protection," in Proceedings of World Dredging Congress XVII, Dredging in a Sensitive Environment (Hamburg: Central Dredging Association). Available online at: https://www.dredging.org/documents/ceda/html_page/publicationswdcxvii- review.pdf

Eckert, S. A., Eckert, K. L., Ponganis, P., and Kooyman, G. L. (1989). Diving and foraging behavior of leatherback sea turtles (Dermochelys coriacea). Can. J. Zool. 67, 2834-2840. doi: 10.1139/z89-399

Finneran, J. J. (2015). Noise-induced hearing loss in marine mammals: a review of temporary threshold shift studies from 1996 to 2015. J. Acoust. Soc. Am. 138, 1702-1726. doi: 10.1121/1.4927418

Fuentes, M. M., Gredzens, C., Bateman, B. L., Boettcher, R., Ceriani, S. A., Godfrey, M. H., et al. (2016). Conservation hotspots for marine turtle nesting in the United States based on coastal development. Ecol. Appli. 26, 2706-2717. doi: 10.1002/eap.1386

Fuentes, M. M. P. B., Blackwood, J., Jones, B., Kim, M., Leis, B., Limpus, C. J., et al. (2015). A decision framework for prioritizing multiple management actions for threatened marine megafauna. Ecol. Appl. 25, 200-214. doi: 10.1890/13-1524.1

Godley, B. J., Blumenthal, J. M., Broderick, A. C., Coyne, M. S., Godfrey, M. H., Hawkes, L. A., et al. (2008). Satellite tracking of sea turtles: where have we been and where do we go next? Endanger. Species Res. 4, 3-22. doi: 10.3354/esr00060

Goldberg, D. W., Almeida, T., Tognin, F., Lopez, G. G., Pizetta, G. T., Junior, N. O., et al. (2015). Hopper dredging impacts on sea turtles on the Northern Coast of Rio de Janeiro State, Brazil. Mar. Turtle Newsl. 147, 16-20.

Goldbogen, J. A., Southall, B. L., DeRuiter, S. L., Calambokidis, J., Friedlaender, A. S., Hazen, E. L., et al. (2013). Blue whales respond to simulated mid-frequency military sonar. Proc. R. Soc. B. 280:20130657. doi: 10.1098/rspb.2013.0657

Halpern, B. S., Walbridge, S., Selkoe, K. A., Kappel, C. V., Micheli, F., D’agrosa, C., et al. (2008). A global map of human impact on marine ecosystems. Science 319, 948-952. doi: 10.1126/science.1149345

Harris, C. M., Thomas, L., Sadykova, D., DeRuiter, S. L., Tyack, P. L., Southall, B. L., et al. (2016). "The challenges of analyzing behavioral response study data: an overview of the MOCHA (multi-study ocean acoustics human effects analysis) project," in The Effects of Noise on Aquatic Life II, eds A. N. Popper and A. Hawkins (New York, NY: Springer), 399-407.

Hazel, J., Lawler, I. R., and Hamann, M. (2009). Diving at the shallow end: green turtle behaviour in near-shore foraging habitat. J. Exp. Mar. Biol. Ecol. 371, 84-92. doi: 10.1016/j.jembe.2009.01.007

Hildebrand, J. A. (2009). Anthropogenic and natural sources of ambient noise in the ocean. Mar. Ecol. Prog. Ser. 395, 5-20. doi: 10.3354/meps08353

Hill, J. E., Robinson, N. J., and King, C. M. P., F. V. (2016). Diving behavior and thermal habitats of gravid hawksbill turtles at St. Croix, USA. Mar. Biol. 164:17. doi: 10.1007/s00227-016-3050-4

Jensen, F. H., Bejder, L., Walhberg, M., Anguilar De Soto, N., Johnson, M. P., and Madsen, P. T. (2009). Vessel noise effects on delphinid communication. Mar. Ecol. Prog. Ser. 395, 161-175. doi: 10.3354/meps08204

Jensen, F. H., Perez, J. M., Johnson, M., Soto, N. A., and Madsen, P. T. (2011). Calling under pressure: short-finned pilot whales make social calls during deep foraging dives. Proc. R. Soc. B. 278, 3017-3025. doi: 10.1098/rspb. 2010.2604 
Johnson, M., Aguilar de Soto, N., and Madsen, P. T. (2009). Studying the behavior and sensory ecology of marine mammals using acoustic recording tags: a review. Mar. Ecol. Prog. Ser. 395, 55-73. doi: 10.3354/meps08255

Johnson, M. P., and Tyack, P. L. (2003). A digital acoustic recording tag for measuring the response of wild marine mammals to sound. IEEE J. Oceanic Eng. 28, 3-12. doi: 10.1109/JOE.2002.808212

Jones, T. T., Van Houtan, K. S., Bostrom, B. L., Ostafichuk, P., Mikkelsen, J., Tezcan, E., et al. (2013). Calculating the ecological impacts of animalborne instruments on aquatic organisms. Methods Ecol. Evol. 4, 1178-1186. doi: 10.1111/2041-210X.12109

Lamont, M. M., Fujisaki, I., Stephens, B. S., and Hackett, C. (2015). Home range and habitat use of juvenile green turtles (Chelonia mydas) in the northern Gulf of Mexico. Anim. Biotelem. 3:53. doi: 10.1186/s40317-015-0089-9

Lavender, A. L., Bartol, S. M., and Bartol, I. K. (2014). Ontogenetic investigation of underwater hearing capabilities in loggerhead sea turtles (Caretta caretta) using a dual testing approach. J. Exp. Biol. 217, 2580-2589. doi: 10.1242/jeb.096651

Lemon, M., Lynch, T. P., Cato, D. H., and Harcourt, R. G. (2006). Response of travelling bottlenose dolphins (Tursiops aduncus) to experimental approaches by a powerboat in Jervis Bay, New South Wales, Australia. Biol. Conserv. 127, 363-372. doi: 10.1016/j.biocon.2005.08.016

Lewison, R. L., Crowder, L. B., Wallace, B. P., Moore, J. E., Cox, T., Zydelis, R., et al. (2014). Global patterns of marine mammal, seabird, and sea turtle bycatch reveal taxa-specific and cumulative megafauna hotspots. Proc. Natl. Acad. Sci. U.S.A. 111, 5271-5276. doi: 10.1073/pnas.1318960111

Lutcavage, M. E., Plotkin, P., Witherington, B., and Lutz, P. (1996). "Human impacts on sea turtle survival," in The Biology of Sea Turtles, eds P. Lutz and J. Musick (Boca Raton, FL: CRC Press), 387-409.

Martin, K. J., Alessi, S. C., Gaspard, J. C., Tucker, A. D., Bauer, G. B., and Mann, D. A. (2012). Underwater hearing in the loggerhead turtle (Caretta caretta): a comparison of behavioral and auditory evoked potential audiograms. J. Exp. Biol. 215, 3001-3009. doi: 10.1242/jeb.066324

McCauley, R. D., Fewtrell, J., Duncan, A. J., Jenner, C., Jenner, M.-N., Penrose, J. D., et al. (2000). Marine seismic surveys - a study of environmental implications. APPEA J. 40, 8.

Merchant, N. D., Fristrup, K. M., Johnson, M. P., Tyack, P. L., Witt, M. J., Blondel, P., et al. (2015). Measuring acoustic habitats. Methods Ecol. Evol. 6, 257-265. doi: 10.1111/2041-210X.12330

Moein, S., Musick, J., Keinath, J., Barnard, D., Lenhardt, M., and George, R. (1994). Evaluation of seismic sources for repelling sea turtles from hopper dredges. Final Report submitted to the US Army Corps of Engineers, Waterways Experiment Station. Virginia Institute of Marine Science (VIMS), College of William and Mary, Gloucester Point, Virginia, 42p.

National Research Council (2000). Marine Mammals and Low-Frequency Sound: Progress Since 1994. Washington, DC: National Academies Press.

National Research Council (2003). Ocean Noise and Marine Mammals. Washington, DC: National Academies Press.

National Research Council (2005). Marine Mammal Populations and Ocean Noise: Determining When Noise Causes Biologically Significant Effects. Washington, DC: National Academies Press.

Nelms, S. E., Piniak, W. E., Weir, C. R., and Godley, B. J. (2016). Seismic surveys and marine turtles: an underestimated global threat? Biol. Conserv. 193, 49-65. doi: 10.1016/j.biocon.2015.10.020

Nowacek, D. P., Thorne, L. H., Johnston, D. W., and Tyack, P. L. (2007). Responses of cetaceans to anthropogenic noise. Mamm. Rev. 37, 81-115. doi: 10.1111/j.1365-2907.2007.00104.x

O'hara, J., and Wilcox, J. R. (1990). Avoidance responses of loggerhead turtles, Caretta caretta, to low frequency sound. Copeia 2, 564-567. doi: $10.2307 / 1446362$

Parks, S. E., Johnson, M., Nowacek, D. P., and Tyack, P. L. (2011). Individual right whales call louder in increased environmental noise. Biol. Lett. 7, 33-35. doi: 10.1098/rsbl.2010.0451

Payne, N. L., Taylor, M. D., Watanabe, Y. Y., and Semmens, J. M. (2014). From physiology to physics: are we recognizing the flexibility of biologging tools? J. Exp. Biol. 217, 317-322. doi: 10.1242/jeb.093922

Piniak, W. E. D. (2012). Acoustic Ecology of Sea Turtles: Implications for Conservation. Ph.D., Duke University.

Piniak, W. E. D., Mann, D. A., Harms, C. A., Jones, T. T., and Eckert, S. A. (2016). Hearing in the juvenile green sea turtle (Chelonia mydas): a comparison of underwater and aerial hearing using auditory evoked potentials. PLOS ONE 11:e0159711. doi: 10.1371/journal.pone.0159711

Popper, A., Hawkins, A., Fay, R., Mann, D., Bartol, S., Carlson, T., et al. (2014). Sound exposure guidelines for fishes and sea turtles: a technical report prepared by ANSI-accredited standards committee S3/SC1 and registered with ANSI. ASA S3/SC1 4

Popper, A. N., and Hastings, M. (2009). The effects of anthropogenic sources of sound on fishes. J. Fish Biol. 75, 455-489. doi: 10.1111/j.1095-8649.2009. 02319.x

Qasem, L., Cardew, A., Wilson, A., Griffiths, I., Halsey, L. G., Shepard, E. L., et al. (2012). Tri-axial dynamic acceleration as a proxy for animal energy expenditure; should we be summing values or calculating the vector? PLoS ONE 7:e31187. doi: 10.1371/journal.pone.0031187

R Core Team (2016). R: A Language and Environment for Statistical Computing. Vienna: R Foundation for Statistical Computing. Available online at: https://www.R-project.org/

Richardson, W. J., Greene, C. R. Jr., Malme, C. I., and Thomson, D. H. (1995). Marine Mammals and Noise. San Diego, CA: Academic Press.

Ridgway, S. H., Wever, E. G., McCormick, J. G., Palin, J., and Anderson, J. H. (1969). Hearing in the giant sea turtle, Chelonia mydas. Proc. Natl. Acad. Sci. U.S.A. 64, 884-890. doi: 10.1073/pnas.64.3.884

Rolland, R. M., Parks, S. E., Hunt, K. E., Castellote, M., Corkeron, P. J., Nowacek, D. P., et al. (2012). Evidence that ship noise increases stress in right whales. Proc. R. Soc. B Biol. Sci. 279, 2363-2368. doi: 10.1098/rspb.2011.2429

Romano, T., Keogh, M., Kelly, C., Feng, P., Berk, L., Schlundt, C., et al. (2004). Anthropogenic sound and marine mammal health: measures of the nervous and immune systems before and after intense sound exposure. Can. J. Fish. Aquat. Sci. 61, 1124-1134. doi: 10.1139/f04-055

Sayigh, L., Quick, N., Hastie, G., and Tyack, P. (2013). Repeated call types in short-finned pilot whales, Globicephala macrorhynchus. Mar. Mamm. Sci. 29, 312-324. doi: 10.1111/j.1748-7692.2012.00577.x

SEFSC, N. (2008). Sea turtle research techniques manual. NOAA Technical Memorandum NMFS-SEFSC 579.

Seminoff, J. A., Jones, T. T., and Marshall, G. J. (2006). Underwater behaviour of green turtles monitored with video-time-depth recorders: what's missing from dive profiles? Mar. Ecol. Prog. Ser. 322, 269-280. doi: 10.3354/meps322269

Signal Developers. (2013). Signal: Signal Processing. Available online at: http://r-forge.r-project.org/projects/signal/

Slabbekoorn, H., and Bouton, N. (2008). Soundscape orientation: a new field in need of sound investigation. Anim. Behav. 76, e5-e8. doi: 10.1016/j.anbehav.2008.06.010

Slabbekoorn, H., Bouton, N., van Opzeeland, I., Coers, A., ten Cate, C., and Popper, A. N. (2010). A noisy spring: the impact of globally rising underwater sound levels on fish. Trends Ecol. Evol. (Amst). 25, 419-427. doi: 10.1016/j.tree.2010.04.005

Southall, B. L., Moretti, D., Abraham, B., Calambokdis, J., DeRuiter, S. L., and Tyack, P. L. (2012). Marine mammal behavioral response studies in southern California: advances in technology and experiemental methods. Mar. Technol. Soc. J. 46, 48-59. doi: 10.4031/MTSJ.46.4.1

Southall, B. L., Nowacek, D. P., Miller, P. J. O., and Tyack, P. L. (2016) Experimental field studies to measure behavioral responses of cetaceans to sonar. Endanger. Species Res. 31, 293-315. doi: 10.3354/esr00764

Stimpert, A. K., DeRuiter, S. L., Southall, B. L., Moretti, D., Falcone, E. A., Goldbogen, J. A., et al. (2014). Acoustic and foraging behavior of a Baird's beaked whale, Berardius bairdii, exposed to simulated sonar. Sci. Rep. 4:7031. doi: 10.1038/srep07031

Stimpert, A. K., Peavey, L. E., Friedlaender, A. S., and Nowacek, D. P. (2012). Humpback whale song and foraging behavior on an Antarctic feeding ground. PLoS ONE 7:e51214. doi: 10.1371/journal.pone.0051214

Sueur, J., Aubin, T., and Simonis, C. (2008). Seewave, a free modular tool for sound analysis and synthesis. Bioacoustics 18, 213-226. doi: 10.1080/09524622.2008.9753600

Sundin, G. W. (2007). Reducing Impacts of Hopper Dredging on Marine Turtles in the Northwestern Gulf of Mexico. Masters of Sciences.

Taquet, C., Taquet, M., Dempster, T., Soria, M., Cirrione, S., Roos, D., et al. (2006). Foraging of the green sea turtle Chelonia mydas on seagrass beds at Mayotte Island (Indian Ocean), determined by acoustic transmitters. Mar. Ecol. Prog. Ser. 306, 295-302. doi: 10.3354/meps306295 
Thomson, J. A., and Heithaus, M. R. (2014). Animal-borne video reveals seasonal activity patterns of green sea turtles and the importance of accounting for capture stress in short-term biologging. J. Exp. Mar. Biol. Ecol. 450, 15-20. doi: 10.1016/j.jembe.2013.10.020

Tyack, P. L. (2009). Acoustic playback experiments to study behavioral responses of free-ranging marine animals to anthropogenic sound. Mar. Ecol. Prog. Ser. 395, 187-200. doi: 10.3354/meps08363

Tyack, P. L., Zimmer, W. M. X., Moretti, D., Southall, B. L., Claridge, D. E., Durban, J. W., et al. (2011). Beacked whales respond to simulated and actual navy sonar. PLoS ONE 6:e17009. doi: 10.1371/journal.pone.0017009

Tyson, R. B., Nowacek, D. P., and Miller, P. J. (2007). Nonlinear phenomena in the vocalizations of North Atlantic right whales (Eubalaena glacialis) and killer whales (Orcinus orca). J. Acoust. Soc. Am. 122, 1365-1373. doi: 10.1121/1.2756263

Tyson, R. B., Piniak, W. E. D., Domit, C., Nowacek, D. P., and Fuentes, M. P. B. (2016). Behavioural response of juvenile green sea turtles (Chelonia mydas) to the FaunaGuard Turtle Module. Final Report submitted to Van Oord (www.VanOord.com). Rotterdam, The Netherlands, 41p.

van der Hoop, J. M., Fahlman, A., Hurst, T., Rocho-Levine, J., Shorter, K. A., Petrov, V., et al. (2014). Bottlenose dolphins modify behavior to reduce metabolic effect of tag attachment. J. Exp. Biol. 217, 4229-4236. doi: $10.1242 /$ jeb. 108225

Van Der Meij, H., Kastelein, R., Van Eekelen, E., and Van Koningsveld, M. (2015). FaunaGuard: a scientific method for deterring marine fauna. Terra et Aqua 138, 17-24.

Van Dolah, R. F., and Maier, P. P. (1993). The Distribution of Loggerhead Turtles (Caretta caretta) in the Entrance Channel of Charleston Harbor, South Carolina, U.S.A. J. Coast. Res. 9, 1004-1012.

Wallace, B. P., Crowder, L. B., Lewison, R. L., McDonald, S. L., McDonald, R. K., Kot, C. Y., et al. (2010). Global patterns of marine turtle bycatch. Conserv. Lett. 3, 131-142. doi: 10.1111/j.1755-263X.2010. 00105.x

Wallace, B. P., DiMatteo, A. D., Bolten, A. B., Chaloupka, M. Y., Hutchinson, B. J., Abreu-Grobois, F. A., et al. (2011a). Global conservation priorities for marine turtles. PLoS ONE 6:e24510. doi: 10.1371/journal.pone. 0024510

Wallace, B. P., Hutchinson, B. J., Mast, R. B., and Pilcher, N. J. (2011b). Putting conservation priority-setting for marine turtles in context. Anim. Conserv. 14, 14-15. doi: 10.1111/j.1469-1795.2011.00439.x

Wallace, B. P., Kot, C. Y., DiMatteo, A. D., Lee, T., Crowder, L. B., and Lewison, R. L. (2013). Impacts of fisheries bycatch on marine turtle populations worldwide: toward conservation and research priorities. Ecosphere 4, 1-49. doi: 10.1890/ES12-00388.1

Weir, C. R. (2007). Observations of marine turtles in relation to seismic airgun sound off Angola. Mar. Turtle Newsl. 116, 17-20.

Wright, A. J., Soto, N. A., Baldwin, A. L., Bateson, M., Beale, C. M., Clark, C., et al. (2007). Do Marine mammals experience stress related to anthropogenic noise? Int. J. Comp. Psychol. 20, 274-316.

Conflict of Interest Statement: The authors declare that the research was conducted in the absence of any commercial or financial relationships that could be construed as a potential conflict of interest.

Copyright (c) 2017 Tyson, Piniak, Domit, Mann, Hall, Nowacek and Fuentes. This is an open-access article distributed under the terms of the Creative Commons Attribution License (CC BY). The use, distribution or reproduction in other forums is permitted, provided the original author(s) or licensor are credited and that the original publication in this journal is cited, in accordance with accepted academic practice. No use, distribution or reproduction is permitted which does not comply with these terms. 